\title{
UTERINE INVERSION DURING CESAREAN SECTION: A RARE PRESENTATION
}

\section{Aisha Khan Jadoon ${ }^{\natural}$, Noureen Anjum'}

\begin{abstract}
INTRODUCTION: Uterine inversion is the collapse of uterine fundus into the endometrial cavity resulting in turning the uterus partially or completely inside out. Uterine inversion during cesarean section is an extremely rare obstetric complication and the exact incidence is not known.

CASE DESCRIPTION: We report complete inversion of uterus in 38-yearold female, Gravida 2 Para I ${ }^{+0}, 38^{+0}$ weeks gestational age, admitted for elective lower segment cesarean section due to previous I scar. Delivery of the baby was uneventful. Complete inversion of uterus through uterine incision was noticed immediately after detachment of placenta. Oxytocin infusion was discontinued immediately, and uterine inversion was reversed manually by exteriorizing uterus and then making a fist and applying force on the fundus. Uterus was closed back in two layers, but it remained relaxed despite, massaging, oxytocin and sublingual misoprostol; therefore, modified B-lynch sutures were applied. This helped the patient to be prevented from any further complications. She was discharged as planned and was stable on follow up visits.
\end{abstract}

CONCLUSION: Uterine inversion was promptly identified and corrected without any major complications.

KEY WORDS: Uterine Inversion (MeSH); Cesarean Section (MeSH); B-lynch sutures (Non-MeSH).

THIS ARTICLE MAY BE CITED AS: Jadoon AK, Anjum N. Uterine inversion during cesarean section: a rare presentation. Khyber Med Univ J 2020; | 3(2): | 23-4. https://doi.org/I0.35845/kmuj.202।.2I 266.

\section{INTRODUCTION}

U erine inversion is a rare obstetric emergency in which the uterus is turned inside out with the prolapse of fundus through the cervix postnatally or through the lower transverse incision during cesarean section. Sometimes, a non-puerperal uterus can undergo inversion but that accounts for $5 \%$ of all cases and of those 97\% are associated with tumors.'If uterine inversion is not diagnosed and reversed in time, the resulting hemorrhage and shock can lead to maternal death. ${ }^{2}$ Some of the causes are retained or abnormally adherent or fundal placenta, uterine atony, short cord, or excessive cord traction, rapid or long labour, previous lower segment cesarean section (LSCS), uterine abnormality/previous inversion, polyhydramnios, certain drugs such as magnesium sulphate and other tocolytics, chronic endometritis, multiparity, macrosomic baby

\section{connective tissue disorders etc.}

We present a case of a 38-year-old woman who suffered uterine inversion during cesarean section that was immediately recognized and managed.

\section{CASE DESCRIPTION}

Patient information: A 38-year-old female booked case, with no known co morbidity, Gravida 2 Para $1^{+0}, 38^{+0}$ weeks gestational age, admitted for elective lower segment cesarean section due to previous I scar. She was a housewife, with $79.5 \mathrm{~kg}$ weight and a height of $158 \mathrm{~cm}$ (Body Mass Index 31.8). Medical, personal, and family history were unremarkable, except that she had a blood transfusion history post cesarean due to anemia but no history of blood loss. Date of admission was I 2/10/2020.

Her investigations were unremarkable in this pregnancy. Complete blood count on showed $\mathrm{Hb} 10.2 \mathrm{gm} / \mathrm{dL}$, TLC
I: Department of Obstetrics and Gynecology, Aga Khan University Hospital, Karachi, Pakistan.

Contact \# : +92-343-2287279

Email网: aishajadoon@hotmail.com

Date Submitted: February 05, 202।

Date Revised: April 25,202I

Date Accepted: April 27, 2021

I I.6x 103/uL, Neutrophils $70.8 \%$. Platelets $37710^{3} / \mathrm{uL}$. On ultrasonography, fetus was growing well and the placenta was localized posterior, left lateral away from internal os.

Clinical Findings: She was vitally stable at the time of admission as well as during surgery. Delivery of the baby was uneventful.

Timeline and diagnostic assessment: Complete inversion of uterus through uterine incision was noticed immediately after detachment of placenta.

Therapeutic Intervention: Oxytocin was stopped. Uterus was exteriorized and reversion was performed immediately and successfully. The uterus was replaced by placing a fist on the fundus and gradually pushing it back into the pelvis through the incision line. Uterus was closed back in two layers, but it remained relaxed despite, massaging, oxytocin and sublingual misoprostol; therefore, modified B-lynch sutures were applied.

Follow-up and Outcomes: Uterus remained well-contracted after that. The patient remained vitally stable and did not go into post-partum hemorrhage (PPH). She was discharged as planned and was found stable on follow up visits.

\section{DISCUSSION}

Uterine inversion is an extremely uncommon obstetric complication. Many obstetricians might have not come across such a case in their entire practice, so diagnosing and treating it becomes a challenge for them. Two commonly proposed etiologies include fundal pressure and excess traction on umbilical cord that is attached to fundus. ${ }^{2}$ 
It is a life-threatening emergency complication that can lead to mortality if not managed timely because it can result in excessive hemorrhage and shock requiring resuscitation. In most of the cases shock is hypovolemic (69\%) and in some it is neurogenic (13\%). Traction to infundibulo-pelvic ligament or stretch of peritoneal or broad ligament might leads to a drop in blood pressure levels or shock that are neurogenic but under anesthesia neurogenic shock is excluded hence hemorrhage becomes the culprit for hemodynamic instability. ${ }^{4}$

The risk of developing this complication in the following pregnancy increases up to $25 \%$ and the incidence is twice more in vaginal deliveries than cesarean section. ${ }^{5}$ It can occur during vaginal delivery, during cesarean and in a nonpuerperal case that can be dealt with certain maneuvers. Manual method also called Johnson maneuver was first explained by Johnson in 1949. It is described as holding the fundus in the palm and keeping the tips of the fingers at the uterocervical junction, the fundus is then raised above the level of the umbilicus. ${ }^{6}$ It can also be used for inversion during cesarean section that we applied in the current case. Similar technique was used in a case reported by Raj Et al in which a 40 -year-old,with no previous scar delivered by cesarean section had an adherent placenta. ${ }^{7}$

Chatzistamatiou K, et al. ${ }^{8}$ also reported a case of uterine inversion in a 34-yearold, 39 weeks pregnant woman, during an elective cesarean section with history of previous I scar and used the same method for reversal. Tocolytics and antibiotics should be administered. If these methods fail, then hysterectomy is performed. ${ }^{6}$

In the case presented Johnson method was used and later Blynch sutures were applied to prevent PPH. It was successfully and promptly managed preventing any morbidity or mortality.

\section{REFERENCES}

I. Atalay MA, Demir BÇ, Solak N, Atalay $F O$, Küçükkömürcü Ş. An unusual presentation of a submucous leiomyoma accounting to a non-puerperal uterine inversion: A case report. J Turk Ger Gynecol Assoc 2013 Jun I; I4(2): I 168. https://doi.org//0.5152/jtgga. 20|3.5563।.

2. Rahaoui M, Zizi H, Mamouni N, Errarhay S, Bouchikhi C, Banani A. Managing major postpartum haemorrhage following acute uterine inversion: a case report and literature review. Sch Int J Obstet Gynec 2020; 3(3): I I0-3. https://doi.org//0.36348/ sijog.2020.v03i03.0I0.
3. Eddaoudi C, Grohs MA, Filali A. Uterine inversion: about a case. Pan Afr Med J 2018; 29:99. https://doi.org/ I0.1 | 604/pamj.2018.29.99.13644.

4. Aruna N, Shobha S, Vijaylakshmi G, Neelamma P. Uterine Inversion During Cesarean Section: A Rare Case. J Evol Med Dental Sci 20 I 4;3(2I): 577 I -4.

5. Baskett TF. Acute uterine inversion: a review of 40 cases. J Obstet Gynaecol Can 2002; 24(I2):953-6. https:// doi.org/I0.1016/SI70I-2I63(I6) 30594-I.

6. Michalska M, Bojar I, Borycki J, Bogdan Z, Brandl S, Kolaciñski R, et al. Postnatal inversion of the uterus management in specific cases. Ann Agric Environ Med2020 Dec 22;27(4): 717-20.https://doi.org/10.26444/ aaem/I305I 2 .

7. Raj A, Roy KK, Zangmo R, Yadav A, Noor $N$, Saha $S$, et al. Uterine inversion during caesarean section: a case report. Int J Reprod Contracept Obstet Gynecol 2020;9(II):4744-6. https://doi.org/10.18203/23201770.ijrcog20204848.

8. Chatzistamatiou K, Daniilidis A, Chatzis P, Vrachnis N, Loufopoulos PD, Tzafettas M, et al. Uterine inversion after controlled cord traction during caesarean section: a case report, Clin ExpObstetGynecol 20 I4;4 I (4):476-7.

\section{AUTHOR'S CONTRIBUTION}

Following authors have made substantial contributions to the manuscript as under:

AKJ: Identification, diagnosis \& management of the case, drafting the manuscript, approval of the final version tobe published

NA: Diagnosis \& management of the case, critical review, approval of the final version to be published

Authors agree to be accountable for all aspects of the work in ensuring that questions related to the accuracy or integrity of any part of the work are appropriately investigated and resolved.

\begin{tabular}{|c|c|c|}
\hline CONFLICT OF INTEREST & \multicolumn{1}{c|}{$\begin{array}{c}\text { Authors declared no conflict of interest } \\
\text { GRANT SUPPORT AND FINANCIAL DISCLOSURE }\end{array}$} \\
$\begin{array}{c}\text { Authors have declared no specific grant for this research from any } \\
\text { funding agency in the public, commercial or not-for-profit sectors }\end{array}$ & $\begin{array}{c}\text { The data that support the findings of this study are available } \\
\text { from the corresponding author upon reasonable request. }\end{array}$ \\
\end{tabular}

This is an Open Access article distributed under the terms of the Creative Commons
Attribution-Non Commercial 2.0 Generic License.

KMUJ web address: www.kmuj.kmu.edu.pk

Email address: kmuj@kmu.edu.pk 